\title{
A Comparative Study between the Use of Negative Pressure Wound Therapy and Silver-Releasing Foam Dressings in the Management of Diabetic Ulcers
}

\author{
George Taliat ${ }^{1}$ Clement D’ Souza ${ }^{1, \odot}$ \\ ${ }^{1}$ Department of Surgery, Father Muller Medical College Hospital, \\ Mangalore, Karnataka, India
}

Int J Recent Surg Med Sci 2022;8:54-58.
Address for correspondence George Taliat, MBBS,MS, Department of Plastic Surgery, M S Ramaiah Medical College, Bengaluru 560054, Karnataka, India (e-mail: georgetaliat@gmail.com).

\begin{abstract}
Introduction Diabetic foot ulcers are one among the most commonly encountered complication of diabetes mellitus tackled by the surgical department worldwide. Negative pressure wound therapy (NPWT) and silver-releasing foam dressings are effective modalities for the treatment of ulcers. This study compares the two treatment modalities.

Methods Sixty adult patients admitted with diabetic foot ulcers undergoing NPWT (vacuum-assisted closure [VAC]) or silver-releasing foam dressing (Biatain Ag) treatment were included in the study. Patients undergoing either of the treatment modalities were observed and followed up on a weekly basis prospectively. Wounds were routinely examined for the size of ulcer in area $\left(\mathrm{cm}^{2}\right)$ and time taken for wound healing. Patients were also assessed qualitatively by means of a questionnaire to find out patient satisfaction and compliance.

Results Time taken for wound healing among Biatain Ag group was found to be

Keywords

- Biatain Ag

- diabetic foot ulcers

- negative pressure wound therapy

- silver-releasing foam dressing

- VAC $24 \pm 9.483$ days compared with only $19.73 \pm 7.575$ days in the VAC group. Decrease in size ulcer measured in area was found to be $38.79 \%$ in Biatain Ag group, whereas in the VAC group it was found to be $26.56 \%$. Patients were satisfied with both modalities of treatment; however, patient compliance was better for the Biatain Ag Group due to decrease in restriction of mobility and decrease in cost.

Conclusion Overall, both modalities of treatment were found to be comparable and can be used with similar efficacy. It can be concluded that silver-releasing foam dressing can act as a beneficial alternative to NPWT in the treatment of diabetic ulcers.
\end{abstract}

\section{Introduction}

Diabetic foot ulcers are one among the most commonly encountered complication of diabetes mellitus tackled by surgical departments worldwide. Patients with diabetes mellitus have up to $25 \%$ lifetime risk of developing foot ulcer. Mainstay of treatment is debridement of all necrotic, callus, and fibrous tissue with the primary goal to obtain wound closure. ${ }^{1}$ With

DOI https://doi.org/

$10.1055 / \mathrm{s}-0041-1739568$

ISSN 2455-7420 rate of amputations being high, causing a strain on quality of life and financial burden on health system, it is important for early treatment and early closure of the wound.

There have been several studies comparing the efficacy of negative pressure wound therapy (NPWT) to conventional care for ulcers. Similarly, there have been several studies comparing silver-releasing foam dressings to other dressings in venous and diabetic ulcer. However, the number of studies 
comparing the two modalities of management of diabetic foot ulcers is limited. Hence, the need for a study comparing these two modalities of treatment is essential.

\section{Silver-Releasing Foam Dressing}

Silver has been used as an antimicrobial for centuries in many formulations. Ionized silver $(\mathrm{Ag}+)$ has both anti-inflammatory and antimicrobial properties, with a broad spectrum of antimicrobial action with no clinical reports of inducing resistant organisms that are human pathogens. Ionic silver appears to be incorporated into the bacterial cell wall and bacterial DNA, thereby blocking vital metabolic processes and cell proliferation. $^{2}$

Many studies have found that they significantly reduce odor, improve pain-related symptoms, decrease wound exudate, and have a prolonged dressing wear time compared with alternative wound treatments. ${ }^{3}$

Biatain $\mathrm{Ag}$ is a soft absorbent polyurethane foam dressing that contains silver ions as an integral part of its matrix. In the presence of wound exudates, ionic silver is released to the wound bed. Biatain $\mathrm{Ag}$ is a dressing that has the dual action of being a foam, which can handle exudate, and containing silver, as an antimicrobial. Due to the silver-releasing profile, there is a continuous antimicrobial effect during the entire wear time (up to 7 days). ${ }^{4}$

There have been several RCTs that show a significant benefit using Biatain Ag for management of hard to heal ulcers. ${ }^{5}$

\section{Negative Pressure Wound Therapy}

NPWT is an innovative technique in managing complex wounds. It was first described by Charikar et al as an experimental technique for treating subcutaneous fistulas. ${ }^{6}$ However, it was the clinical work by Argenta and Morykwas a decade later that allowed NPWT to gain recognition as a useful clinical tool for managing complex and difficult wounds. ${ }^{7}$

NPWT is thought to improve dermal blood flow through vasomotor mediators. Direct macrodeformation induced by NPWT leads to wound contraction and size reduction. This is an important mechanism that reduces large defects in diabetic wounds after radical debridement. ${ }^{8}$ NPWT also induces angiogenesis and vascular proliferation. Clinical trials in diabetic wounds have also demonstrated NPWT's superiority in producing granulation compared with conventional dressings. ${ }^{9}$ NPWT removes excess wound fluid that not only reduces edema but also enhances local blood and nutrient flow. ${ }^{10}$ Furthermore, NPWT mobilizes the systemic endothelial progenitor cells that are markers of healing and repair. ${ }^{11}$

\section{NPWT and Silver Antimicrobials}

Silver foam has been used in adjunction with NPWT. Nanocrystalline silver provides a continuous flow of charged silver cation particles. These can be used instead of regular foam. Foam dressings such as Granufoam are used to provide both the antimicrobial properties of silver as well as act as a medium for effective NPWT. ${ }^{12}$

\section{Materials and Methods}

\section{Source of Data}

It is a prospective comparative study using a sample size of 60 patients (30 in each group) using purposive sampling technique based on inclusion and exclusion criteria. The study includes all indicated patients undergoing said treatments modalities in surgery department in a single tertiary hospital over a period of 2 years.

\section{Inclusion Criteria}

1. All patients above 18 years of age diagnosed to have an ulcer as a complication of diabetes mellitus.

2. Patients with ulcers having hemoglobin A1c (HbA1c) of over 6.5.

\section{Exclusion Criteria}

1. Patients with ulcers having HbA1c lesser than 6.5.

2. Patients with proven malignancy.

3. Patients with proven venous ulcers.

\section{Method of Collection of Data}

Patients who were admitted for diabetic foot ulcers were observed based on the treatment provided by the primary treating doctor and followed up. Treatment modality was decided by the treating doctor after discussing the options with the patients. Informed consent was taken from the patients.

NPWT was provided using vacuum-assisted closure (VAC) devices along with foam dressing and waterproof adhesive. NPWT of $-125 \mathrm{~mm} \mathrm{Hg}$ was applied by the same provider using the same company-based materials.

Silver-releasing foam dressing was provided by the use of dressing material namely Biatain Ag (nonadhesive).

Both groups of patients underwent adequate wound debridement prior to application. Both groups of patients had the respective dressing on the ulcer for 5 days before next change of dressing. Patients were followed up regularly to assess complete wound healing or until deemed fit to undergo closure via skin grafting or secondary closure. In the event of nonhealing of ulcer by end of 4 months, reduction in area of ulcer in $\mathrm{cm}^{2}$ was assessed and compared. At the end of wound healing or by 4th month, patients were followed up with a questionnaire to assess patient compliance and satisfaction with treatment (-Table $\mathbf{1}$ ).

\section{Statistical Analysis}

The collected data was analyzed by chi-squared tests and Mann-Whitney $U$ test and the data was analyzed using $p$-value. A value of less than 0.05 was considered statistically significant.

\section{Results}

Age distribution among both the groups was comparable with no significant difference. It was noted that there were significantly more males in both the groups than females. 
Table 1 Qualitative assessment questionnaire

\begin{tabular}{|c|c|c|c|c|c|}
\hline & $\begin{array}{l}\text { Strongly } \\
\text { disagree }(-2)\end{array}$ & $\begin{array}{l}\text { Somewhat } \\
\text { disagree }(-1)\end{array}$ & $\begin{array}{l}\text { Neutral } \\
(0)\end{array}$ & $\begin{array}{l}\text { Somewhat } \\
\text { agree (1) }\end{array}$ & $\begin{array}{l}\text { Strongly } \\
\text { agree (2) }\end{array}$ \\
\hline \multicolumn{6}{|l|}{$\begin{array}{l}\text { 1. My condition was interfering with my } \\
\text { daily activity and caused me much } \\
\text { discomfort }\end{array}$} \\
\hline \multicolumn{6}{|l|}{$\begin{array}{l}\text { 2. I feel my ulcer has indeed healed cur- } \\
\text { rently after the treatment }\end{array}$} \\
\hline \multicolumn{6}{|l|}{$\begin{array}{l}\text { 3. The treatment modality that I received } \\
\text { was essential in the healing/improve- } \\
\text { ment of the ulcer }\end{array}$} \\
\hline \multicolumn{6}{|l|}{$\begin{array}{l}\text { 4. The treatment modality that I received } \\
\text { was too expensive }\end{array}$} \\
\hline \multicolumn{6}{|l|}{$\begin{array}{l}\text { 5. The treatment modality that I received } \\
\text { was difficult to comply with }\end{array}$} \\
\hline \multicolumn{6}{|l|}{$\begin{array}{l}\text { 6. I found it difficult to go about my daily } \\
\text { activities due to my treatment }\end{array}$} \\
\hline $\begin{array}{l}\text { 7. Further comments on treatment modal- } \\
\text { ity received }\end{array}$ & & & & & \\
\hline
\end{tabular}

Wounds were compared between Biatain Ag group (-Fig. 1) and VAC group (-Fig. 2).

With regard to time taken for wound healing, Biatain $\mathrm{Ag}$ group took a mean of 24 days with a standard deviation of 9.483 and a median of 21.5 days. VAC group took a mean of 19.73 days with a standard deviation of 7.575 and a median of 18 days. Statistical significance could not be established, however, as p-value was 0.079 (-Table 2).

Comparing percentage of decrease in ulcer, area was calculated in $\mathrm{cm}^{2}$ at the beginning of treatment and at the time of definitive treatment. Percentage of decrease in area of ulcer was noted in each group.

Biatain Ag showed a mean 38.79\% decrease in size, whereas VAC group showed $26.56 \%$ mean decrease in size of ulcer. This was found to be statistically significant with a p-value of 0.035 ( - Table 3 ).

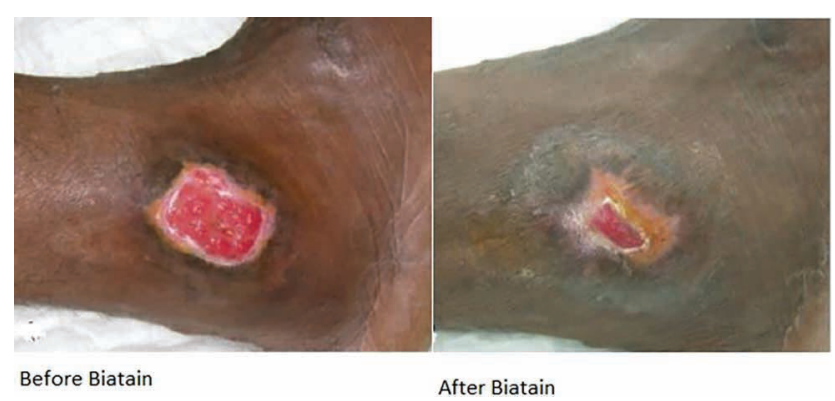

Fig. 1 Effects of Biatain Ag.

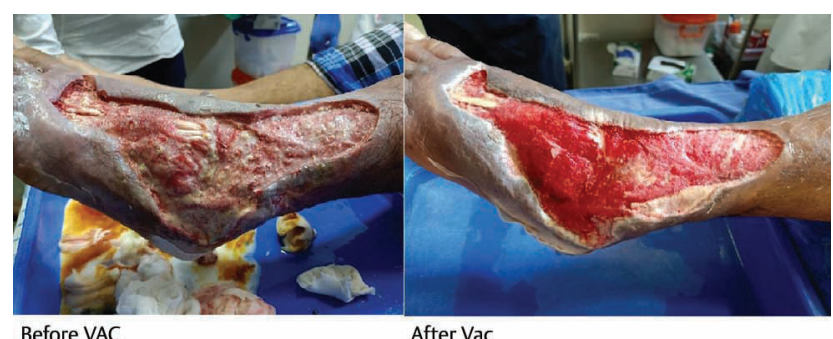

Fig. 2 Effects of vacuum-assisted closure.
Table 2 Time taken for wound healing (days)

\begin{tabular}{|c|c|c|c|c|c|c|}
\hline \multirow[t]{2}{*}{ Groups } & \multirow[t]{2}{*}{$N$} & \multirow[t]{2}{*}{ Mean } & \multirow{2}{*}{$\begin{array}{l}\text { Standard } \\
\text { deviation }\end{array}$} & \multirow[t]{2}{*}{ Median (IQR) } & \multicolumn{2}{|c|}{ Mann Whitney Test } \\
\hline & & & & & Z-Value & $p$-Value \\
\hline BIATAIN AG & 30 & 24.00 & 9.483 & $\begin{array}{l}21.5(17.5- \\
28.25)\end{array}$ & 1.754 & 0.079 \\
\hline VAC & 30 & 19.73 & 7.575 & $18(12-24.25)$ & & \\
\hline
\end{tabular}

Table 3 Percentage of decrease in area of ulcer

\begin{tabular}{|l|l|l|l|l|l|l|}
\hline Groups & $N$ & Mean & $\begin{array}{l}\text { Standard } \\
\text { deviation }\end{array}$ & Median (IQR) & \multicolumn{2}{|l|}{ Mann Whitney U-rest } \\
\cline { 5 - 7 } & & & Z-Value & $p$-Value \\
\hline BIATAIN AG & 30 & 38.79 & 22.853 & $43.645(20-55)$ & 2.112 & 0.035 \\
\hline VAC & 30 & 26.56 & 20.233 & $25(13.1225-40)$ & \multicolumn{2}{|c|}{ Sig } \\
\hline
\end{tabular}

\section{Qualitative Assessment}

Majority (90\%) of the patients did feel that the ulcer was interfering with their daily activities and caused much discomfort in both groups.

Both groups of patients did feel satisfied that their ulcer had indeed healed: Biatain Ag group-86.6\% and the VAC group-90\%.

When asked whether they felt the given treatment modality indeed helped in ulcer healing, 83.3\% agreed in Biatain $\mathrm{Ag}$ group as opposed to $100 \%$ in the VAC group.

When asked whether the patient felt the treatment modality was too expensive in Biatain Ag group, 43.3\% agreed as opposed to $63.3 \%$ in VAC group.

Forty percent patients receiving Biatain Ag did not agree that the treatment was too expensive, while $13.4 \%$ in VAC did not feel that it was too expensive.

About $43.3 \%$ patients in Biatain Ag group felt it difficult to comply with the treatment, whereas this number was at $63.3 \%$ with VAC group.

When asked whether their treatment made it difficult for the patient to go about their daily activities, $60 \%$ agreed in Biatain group, whereas $96.7 \%$ agreed in VAC group (- Table 4 ). 
Table 4 Qualitative assessment results

\begin{tabular}{|c|c|c|c|c|c|c|c|}
\hline & & \multicolumn{6}{|c|}{ Groups } \\
\hline & & \multicolumn{2}{|c|}{ BIATAIN AG } & \multicolumn{2}{|c|}{ VAC } & \multicolumn{2}{|r|}{ Total } \\
\hline & & Count & Column N \% & Count & Column N\% & Count & Column N\% \\
\hline \multirow[t]{4}{*}{ Q1 } & -1 & 0 & 0 & 2 & 6.7 & 2 & 3.3 \\
\hline & 0 & 1 & 3.3 & 3 & 10.0 & 4 & 6.7 \\
\hline & 1 & 14 & 46.7 & 17 & 56.7 & 31 & 51.7 \\
\hline & 2 & 15 & 50.0 & 8 & 26.7 & 23 & 38.3 \\
\hline \multirow[t]{4}{*}{ Q2 } & -1 & 2 & 6.7 & 0 & .0 & 2 & 3.3 \\
\hline & 0 & 2 & 6.7 & 3 & 10.0 & 5 & 8.3 \\
\hline & 1 & 13 & 43.3 & 11 & 36.7 & 24 & 40.0 \\
\hline & 2 & 13 & 43.3 & 16 & 53.3 & 29 & 48.3 \\
\hline \multirow[t]{3}{*}{ Q3 } & 0 & 5 & 16.7 & 0 & .0 & 5 & 8.3 \\
\hline & 1 & 9 & 30.0 & 8 & 26.7 & 17 & 28.3 \\
\hline & 2 & 16 & 53.3 & 22 & 73.3 & 38 & 63.3 \\
\hline \multirow[t]{5}{*}{ Q4 } & -2 & 1 & 3.3 & 0 & .0 & 1 & 1.7 \\
\hline & -1 & 4 & 13.3 & 0 & .0 & 4 & 6.7 \\
\hline & 0 & 10 & 33.3 & 3 & 10.0 & 13 & 21.7 \\
\hline & 1 & 13 & 43.3 & 12 & 40.0 & 25 & 41.7 \\
\hline & 2 & 2 & 6.7 & 15 & 50.0 & 17 & 28.3 \\
\hline \multirow[t]{5}{*}{ Q5 } & -2 & 5 & 16.7 & 2 & 6.7 & 7 & 11.7 \\
\hline & -1 & 7 & 23.3 & 2 & 6.7 & 9 & 15.0 \\
\hline & 0 & 5 & 16.7 & 7 & 23.3 & 12 & 20.0 \\
\hline & 1 & 12 & 40.0 & 18 & 60.0 & 30 & 50.0 \\
\hline & 2 & 1 & 3.3 & 1 & 3.3 & 2 & 3.3 \\
\hline \multirow[t]{5}{*}{ Q6 } & -2 & 1 & 3.3 & 0 & .0 & 1 & 1.7 \\
\hline & \begin{tabular}{|l}
-1 \\
\end{tabular} & 3 & 10.0 & 0 & .0 & 3 & 5.0 \\
\hline & 0 & 8 & 26.7 & 1 & 3.3 & 9 & 15.0 \\
\hline & 1 & 15 & 50.0 & 20 & 66.7 & 35 & 58.3 \\
\hline & 2 & 3 & 10.0 & 9 & 30.0 & 12 & 20.0 \\
\hline
\end{tabular}

\section{Discussion}

Diabetic foot ulcers being one of the common complications of diabetes mellitus which in itself is an extremely common disease, it is an imperative to innovate newer modalities of treatment. They cause significant distress to the patients who are often unable to carry out their daily activities. Furthermore, if left untreated, the patient may succumb to secondary infection leading to sepsis and in some cases even death. Adequate and rapid healing is of utmost importance to most patients. Various dressing materials and techniques have been adopted and studied in the past and even more are being developed. In this study, we have compared two effective methods of closure of diabetic ulcers namely NPWT (VAC) and silver-releasing foam dressings (Biatain Ag). Although there have been various studies comparing each of these treatment modalities with conventional gauze dressings, there are very few directly comparing these modalities.

A study conducted by McCallon et al observed a decrease of $28.4 \%$ in wound size in VAC group as compared with $9.5 \%$ in those treated with saline moistened gauze dressing. ${ }^{13}$ This was comparable to our study that showed a mean decrease of $26.56 \%$ in patients treated with VAC. However, we compared this with Biatain $\mathrm{Ag}$ dressing that showed 38.79\% decrease in wound size that is statistically significant with a $p$-value of 0.035 .

According to a study done by Karlsmark et al antibacterial activity of silver in a silver-releasing foam dressing is very efficient and has excellent exudates management. There was a significant reduction in size of ulcer $56 \%$ in those treated with silver-releasing foam dressing namely Contreet foam. ${ }^{3}$ This was significantly different from our study that shows only a mean decrease of $38.79 \%$ with Biatain Ag. Studies would have to be conducted to compare these two types of silver-releasing foam dressings.

In a study by Günal et al that compared Granufoam dressings with VAC Granufoam silver dressings, it was found that average duration of treatment for plain Granufoam dressings was 25.5 days, whereas in VAC Granufoam silver dressings, the average time for wound healing was only 10.09 days. ${ }^{14}$ In our study, Biatain Ag group took $24 \pm 9.483$ days and in the VAC group it took $19.73 \pm 7.575$ days for wound healing. Although VAC took lesser time for wound healing, it was not statistically significant with a $p$-value of 0.079 .

It is important to note that the initial size of ulcer in the group undergoing VAC therapy did have significantly larger pretreatment area of $54.3 \mathrm{~cm}^{2}$ compared with that of Biatain Ag group that had a pretreatment mean size of $36.16 \mathrm{~cm}^{2}$.

Time taken for wound healing was deemed an important parameter for most patients. It reduced the hospital stay and overall burden on the patient for the treatment.

Size of the ulcer did significantly reduce more in the Biatain Ag group that has the advantage of facilitating a secondary suturing as opposed to skin grafting or flap covers. This is especially significant as grafting or flap covers require another major surgery that is added cost and morbidity to the patient (donor site pain, infection, etc.).

Amount of granulation tissue was not taken into consideration as it may not be accurate and can have observer side errors in calculations; however, it is worth noting that the reduced time taken for wound healing in NPWT group was mainly attributed to better granulation formation.

Also, worth noting is the fact that we did not take depth and grade of ulcer into consideration. VAC dressings are usually preferred in patients with a larger depth of ulcer and this was seen in our study as well wherein Biatain was not preferred in very deep ulcers.

It is important to note at this juncture that even though both modalities of treatment are extremely helpful in their own way, they will never replace a surgical debridement prior to applying either of these. Physical removal of slough and biofilm is important in rapid healing. This is the area where NPWT triumphs over silver-releasing foam dressings as they involve regular suctioning of the slough within the ulcer.

Another important parameter that needs to be checked is the microbiological index of an ulcer. Wounds with positive culture reports of pathogenic microbes are not fit for skin grafting and may result in graft rejection. This is another area that previous studies have shown a benefit for silver-releasing foam dressing due to its antimicrobial properties. Studies conducted by Karlsmark et al and Rayman et al concluded that reduction in size of ulcer may be attributed to its superior antibacterial activity. ${ }^{3,15}$

Considering the various studies done previously, it is worth considering combining both modalities of treatment. Many studies have shown that use of silver-releasing foam instead of the inert foam gives an added antimicrobial property to NPWT. Availability of such foams should be made more accessible. Furthermore, surgeons have tried 
alternating between NPWT and silver-releasing foam dressings depending on level of infection and granulation tissue formed. These are areas that need further studies.

In our study, we took into account the quality of life of the patients by means of a questionnaire where it was evident that while patients were equally content with both treatment modalities and were more satisfied with VAC in healing of ulcer, majority of patients felt that VAC was too expensive and difficult to comply with mainly due to the hindrance to daily activities.

Patients in the Biatain Ag group were also quite satisfied that they had the liberty to walk and, in many instances, could be discharged from the hospital thereby reducing hospital stay. Even though few cases in VAC therapy were allowed to mobilize and even be discharged, majority of them were hospitalized and were not satisfied that it hampered their daily activities. Early mobilization of patients postoperatively also prevents adverse effects such as deep vein thrombosis, pressure sores, lower respiratory tract infection, or muscle wasting. Moreover, it improves collateral supply to the limb thereby helping in faster healing of the wound. Patients themselves would be more encouraged psychologically if allowed to continue their daily activities.

In our study, patients felt that VAC dressings to be expensive causing a financial burden as compared with those in Biatain Ag Group.

Patients were asked for any further comments or complaints about their treatment modality. One common complaint in the Biatain Ag Group was that dressings often got soaked by the 5th day and there was a foul odor associated with it. With VAC therapy patients also reported feeling mild dragging pain associated with the constant suction.

Overall, both modalities of treatment were found to be comparable and can be used interchangeably. The use of silver-releasing foam dressings along with NPWT need to be considered as well. Significant reduction in size and better patient compliance indicate that silver-releasing foam dressing may be a better choice. However, this may not apply very well for larger ulcers with slough for which NPWT works better. The added expense of NPWT also discourages the patient and further effort must be made to reduce the cost of such procedures. It can be concluded that silver-releasing foam dressing can act as a very beneficial alternative to NPWT in the treatment of diabetic ulcers.

\section{Conclusion}

NPWT has been used widely for the rapid healing of diabetic ulcers by promoting granulation tissue. However, this study found that time taken for wound healing was statistically similar to silver-releasing foam dressings. Furthermore, silver-releasing foam dressings had the added advantage that they showed significant decrease in ulcer size and had better patient compliance and was more cost effective. It can be concluded that silver-releasing foam dressings can be used as a good alternative to NPWT for diabetic foot ulcers.

\section{Conflict of Interest}

None declared.

\section{References}

1 Madden JW. Wound healing: the biological basis of hand surgery. Clin Plast Surg 1976;3(1):3-11

2 Cohen IK. Lessons from the history of wound healing. Clin Dermatol 2007;25(1):3-8

3 Karlsmark T, Agerslev RH, Bendz SH, Larsen JR, Roed-Petersen J, Andersen KE. Clinical performance of a new silver dressing, Contreet Foam, for chronic exuding venous leg ulcers. J Wound Care 2003;12(9):351-354

4 Humbert P, Zuccarelli F, Debure C, et al. Ulcères de jambe présentant des signes locaux d'infection: intérêt du pansement Biatain Argent. [Leg ulcers showing local signs of infection: benefits of the Biatain Argent dressing]. J des plaies et Cicatrisations 2006;52:41-47

5 Chambers H, Dumville JC, Cullum N. Silver treatments for leg ulcers: a systematic review. Wound Repair Regen 2007;15(2):165-173

6 Chariker ME, Jeter KF, Tintle TE, Bottsford JE. Effective management of incisional and cutaneous fistulae with closed suction wound drainage. Contemp Surg 1989;34:59-63

7 Argenta LC, Morykwas MJ. Vacuum-assisted closure: a new method for wound control and treatment: clinical experience. Ann Plast Surg 1997;38(6):563-576

8 Schintler MV. Negative pressure therapy: theory and practice. Diabetes Metab Res Rev 2012;28(Suppl 1):72-77

9 Kopp J, Hoff C, Rosenberg B, et al. Application of VAC-therapy upregulates growth factor levels in neuropathic diabetic foot ulcers. Wound Repair Regen 2003;11:7

10 Lu X, Chen S, Li X. The experimental study of the effects of vacuum-assisted closure on edema and vessel permeability of the wound. Chin J Clin Rehab 2003;7:1244-1245

11 Seo SG, Yeo JH, Kim JH, Kim JB, Cho TJ, Lee DY. Negative-pressure wound therapy induces endothelial progenitor cell mobilization in diabetic patients with foot infection or skin defects. Exp Mol Med 2013;45:e62

12 Fong J, Wood F. Nanocrystalline silver dressings in wound management: a review. Int J Nanomedicine 2006;1(4):441-449

13 McCallon SK, Knight CA, Valiulus JP, Cunningham MW, McCulloch JM, Farinas LP. Vacuum-assisted closure versus saline-moistened gauze in the healing of postoperative diabetic foot wounds. Ostomy Wound Manage 2000;46(8):28-32

14 Günal Ö, Tuncel U, Turan A, Barut S, Kostakoglu N. The use of vacuum-assisted closure and GranuFoam Silver ${ }^{\circledR}$ dressing in the management of diabetic foot ulcer. Surg Infect (Larchmt) 2015;16(5):558-565

15 Rayman G, Vas P, Dhatariya K, et al. International Working Group on the Diabetic Foot (IWGDF). Guidelines on use of interventions to enhance healing of chronic foot ulcers in diabetes (IWGDF 2019 update). Diabetes Metab Res Rev 2020;36(Suppl 1):e3283 